\title{
BACTERIOLOGICAL QUALITY OF SACHET WATER PRODUCED AND SOLD IN TESHIE-NUNGUA SUBURBS OF ACCRA, GHANA
}

\author{
Addo KK ${ }^{* 1}$, Mensah GI ${ }^{1}$, Bekoe $\mathbf{M}^{1}$, Bonsu $C^{1}$ and ML Akyeh ${ }^{1}$
}

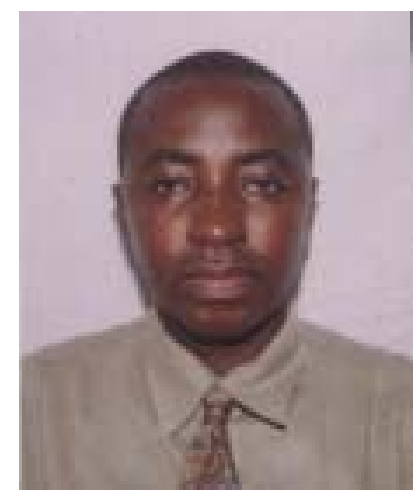

Addo Kennedy

*Corresponding author - Email: kaddo@noguchi.mimcom.org

${ }^{1}$ Bacteriology Department, Noguchi Memorial Institute for Medical Research, University of Ghana, P. O. Box LG 581, Legon-Accra, Ghana. 


\section{ABSTRACT}

Access to good quality drinking water is a challenge in most towns and cities in Ghana and households have for years depended on other sources of water to supplement their activities. The introduction of sachet water to consumers was to provide safe, hygienic and affordable instant drinking water to the public. Although this is a laudable idea, current trends seem to suggest that sachet drinking water could be a route of transmission of diseases. The objective of this study was to determine the bacteriological quality of sachet water popularly known as "pure water" produced and sold in the Teshie-Nungua suburbs of Accra, Ghana, one of the areas with perennial water shortage forcing inhabitants to depend on sachet water as a source of drinking water. Using simple random sampling procedures, 30 samples from 10 brands of sachet water were collected from hawkers/vendors in Teshie-Nungua (3 samples per brand). One sachet water sample was taken from each site every fortnight for six weeks in May-June 2007. The samples were analyzed using multiple tube method and biochemical assays. Results were recorded as Most Probable Number (MPN) of coliform per $100 \mathrm{ml}$ of water. The bacteriological quality of the samples was assessed based on the World Health Organization (WHO) classification system for drinking water. Five $(16.7 \%)$ of the samples were Excellent, 5 (16.7\%) were Satisfactory, 9 (30\%) were Suspicious and 11 (36.7\%) were Unsatisfactory using the MPN values recorded. Six samples were contaminated with faecal coliform and two of these, (P1 and P2) were from the same brand. Escherichia coli was also detected in the two samples (P1 and P2) out of three samples from the same brand. The level of contamination could be due to inadequate treatment of water samples by the producers, improper use of filters or post-production contamination. The findings suggest the need to enforce the laws that govern the operation of such production outfits as well as educating consumers on the need to purchase sachet water from manufacturers that have been licensed to produce water and whose product bears the stamp of the Food and Drugs Board of Ghana.

Key words: Sachet Water, Coliform, E. coli, MPN

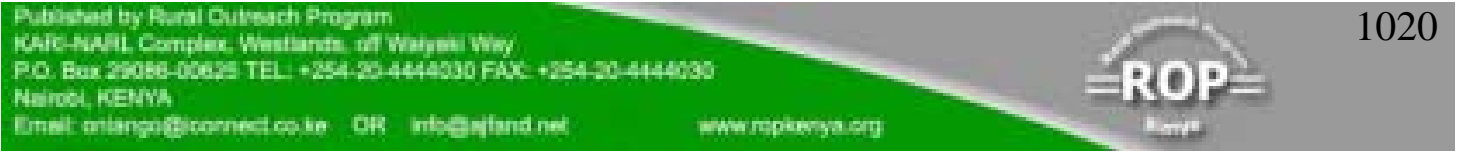




\section{INTRODUCTION}

Accessibility and availability of fresh clean water is key to sustainable development and an essential element in health, food production and poverty reduction [1]. However, safe drinking water remains inaccessible for about 1.1 billion people in the world and the hourly toll from biological contamination of drinking water is 400 deaths of children below age five [2].

In Ghana, the supply of piped water is inadequate in most communities. This inadequacy is both in quantity and quality of the public water supply. Only about 10.3 million people (approx. 51\% of the population) are reported to have access to improved water supplies [3]. Those who do not have access to safe water, as well as those who have access but cannot afford, rely on other sources of water with questionable quality.

The microbiological quality of drinking water is a concern to consumers, water suppliers, regulators and public health authorities. The potential of drinking water to transmit microbial pathogens to great number of people causing subsequent illness is well documented in many countries at all levels of economic development [4]. The number of outbreaks that have been reported throughout the world demonstrates that transmission of pathogens by drinking water remains a significant cause of illness. However, estimate of illness based solely on detected outbreaks is likely to underestimate the problem. A significant proportion of water-borne illnesses are likely to go undetected by the communicable diseases surveillance reporting systems. The symptoms of gastrointestinal illness (nausea, diarrhea, vomiting and abdominal pain) are usually mild and generally last a few days to a week and only a small percentage of those affected will visit a health facility [4].

In Ghana most consumers get water supply from sources other than the Ghana Water Company Limited (GWCL) via their taps because only $40 \%$ of the total urban population is directly covered by the GWCL's networks [3]. The safety of the water obtained from sources other than the GWCL cannot be ascertained hence the water is mostly used for other household activities rather than for direct consumption. The most reliable source of drinking water is bottled water which is of good bacteriological quality [5] but it is expensive and thus only within the means of the affluent in the society.

As an alternative, small-scale industries have come up with sachet water popularly known as "PURE WATER". This product is $500 \mathrm{ml}$ of water in clear nylon square sachets which have been electrically heated and sealed at both ends and widely patronized by both low and middle income earners. The production of sachet water has increased tremendously with over 300 registered producers and 600 unregistered in Ghana [6]. According to the Food and Drugs Board of Ghana, majority of sachet water are produced under questionable hygienic environmental conditions and they have had cause to impose a ban on some producers. Besides, some products do not bear the stamp of approval of the Food and Drugs Board. Even those who have registered do not always meet the standard required of them. Regardless of all these

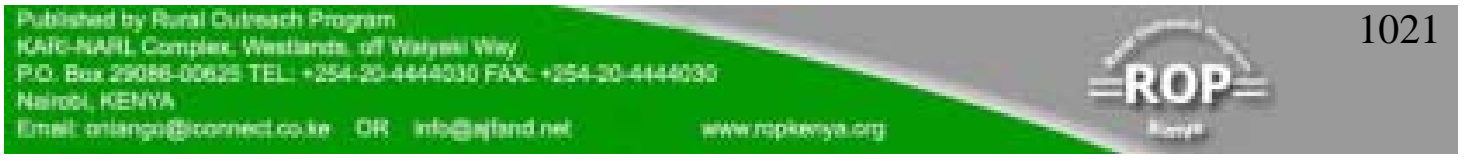


problems, the production of sachet water enjoys a high patronage because apart from affordability, it is considered wholesome for drinking purposes as compared to tap or well water.

This study was undertaken to determine the bacteriological quality of sachet water popularly known as "pure water" produced and sold in the Teshie-Nungua suburbs of Accra, Ghana, one of the areas with perennial water shortage forcing inhabitants to depend on sachet water as a source of drinking water.

\section{MATERIALS AND METHODS}

\section{Study/Sampling Sites}

Teshie and Nungua are adjoining old fishing towns with high population densities that are now considered suburbs of Accra. They were selected for the investigation as these towns are well noted for their perennial water shortage. This has resulted in residents buying buckets of water from private vendors. This water transported in tankers is of questionable quality hence is mostly used for household activities while sachet water believed to be pipe-borne water that has undergone further treatment is relied upon by many residents for the purposes of drinking. With the obvious demand for "pure water", small scale industries have sprung up overnight producing sachet water to meet the demand.

The selected sites were visited prior to the start of the project and the study explained to the vendors. The vendors were recruited into the study after they had given their consent with the assurance of confidentiality. The production of the sachet water was also observed at some production sites to get an insight into measures employed to prevent contamination during the processing. Ten vendors at different sites were recruited and one sample was taken from each vendor every fortnight for six weeks (a total of three samples from each vendor). Sampling was done between 10-11am in May-June 2007 and transported to the bacteriology laboratory of the Noguchi Memorial Institute for Medical Research, Legon on ice packs within hours after collection. The samples were taken through bacteriological examination immediately. Analysis was to determine most probable number (MPN) of coliform organisms per mililitre of each sachet water as well as to determine the presence of pathogenic bacteria such as Escherichia coli.

\section{Production of sachet water}

Tap water is collected into a reservoir and is treated with chlorine tablet (1500 gallons to 1 tablet). The water is then pumped into an overhead tank through four sets of filters with pore size of 5 micron each.

The water descends or flows with force into four other sets of filters, two with pore size of 1 micron and the other two with pore size of 0.5 micron.

The water then passes through carbon into a stainless steel ultra violet machine before finally passing through a packaging machine where it is automatically packed into

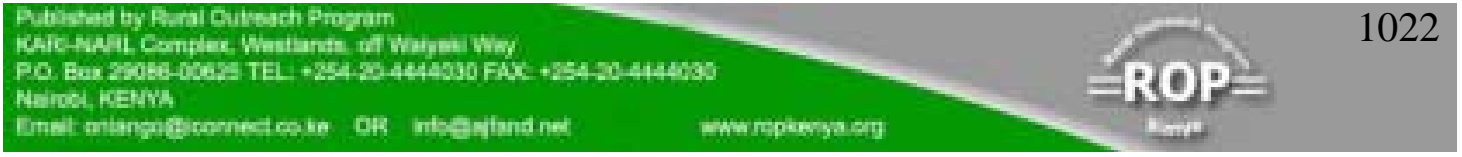


sachets $(500 \mathrm{ml})$. In built in the machine is an ultra violet light that casts on the roll of the rubber for packaging.

\section{Inoculation and Incubation}

One end of each sample of sachet water was cleaned with $70 \%$ ethanol. A sterile pair of scissors was used to cut open each sachet of water at the sterilized end. Ten millilitres $(10 \mathrm{ml})$ of sample was measured with a sterile $10 \mathrm{ml}$ disposable pipette (Sarstedt) and aseptically dispensed into each of the five tubes containing $10 \mathrm{ml}$ of double strength purple MacConkey broth (Oxoid CM5a) each with an inverted Durham tube. One milliliter of the same sample was dispensed into five tubes and $0.1 \mathrm{ml}$ also dispensed into another five tubes all containing the single strength purple MacConkey broth. The tubes were closed tightly and then shaken to distribute the sample uniformly throughout the medium and then incubated at $37^{\circ} \mathrm{C}$. The procedure was carried out in a clean-lighted flow hood. The chamber was always disinfected with $70 \%$ alcohol before and after the analysis.

After 24-48 hours, the tubes from the presumptive fermentation test showing gas and acid formation were recorded and corresponding Most Probable Number (MPN) index was determined from the probability table (McCrady). A sterile pipette was used to transfer $1 \mathrm{ml}$ of the culture from the positive presumptive fermentation tubes into tubes containing $5 \mathrm{ml}$ brilliant green lactose bile broth (BioMerieux 69260) aseptically and incubated for $24-48 \mathrm{hrs}$ at $37^{\circ} \mathrm{C}$.

Following incubation, aliquots from the cultured positive tubes were aseptically streaked on MacConkey agar (Oxoid CM7) for total coliform and Eosin Methylene Blue agar [EMB (Oxoid CM69)] for faecal coliform and incubated at $37^{\circ} \mathrm{C}$ and $44^{\circ} \mathrm{C}$, respectively. Colonies suspected to be coliform and faecal coliform were identified through biochemical tests utilizing Triple Sugar Iron (TSI) agar, Sulphur Indole Motility (SIM) agar, Simons Citrate agar and Urea agar.

Data was analyzed using EpiInfo version 6 software. The analysis was to compare the microbial load of the different brands of sachet water and to determine which brands met the required criteria for treated drinking water. Samples were always analyzed on individual basis.

\section{RESULTS}

The brands of sachet water were rated based on the mean MPN values of the three samples as shown in Table 1. Only two brands (KD and G) met the World Health Organization (WHO) criteria which states that not more than 1 out of 10 analytical units should have an MPN value of $>2.2$ and that sample should have an MPN value not exceeding 9.2 [7]; four of the brands $\mathrm{S}, \mathrm{B}, \mathrm{P}$ and $\mathrm{K}$ did not meet the criteria because they had MPN values greater than 2.2.

Faecal coliform was detected in 6 samples (30\%) belonging to the P1, P2, ST, G, J and $\mathrm{K}$ brands. Two of the three samples of brand P (P1 and P2) were found to be contaminated with E. coli (Table 2).

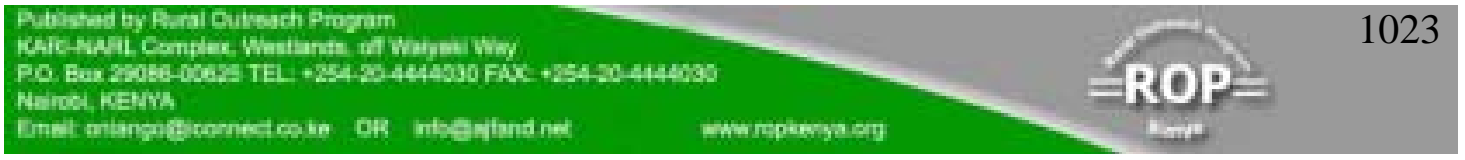


Using the MPN values, the quality of individual sachet water samples was classified as Excellent (<2MPN/100ml), Satisfactory (1-3 MPN/100ml), Suspicious (410MPN/100ml) and Unsatisfactory (>10MPN/100ml) (Table 3), based on a WHO classification system for drinking water [7].

A small percentage of the individual samples was found to be Excellent (16.7\%) and Satisfactory (16.7\%) but a greater number $(30 \%)$ and $(36.7 \%)$ were considered to be of suspicious and unsatisfactory quality, respectively (Table 3).

\section{DISCUSSION}

The 30 samples, based on the MPN values were classified as Excellent, Satisfactory, Suspicious and Unsatisfactory. The WHO guidelines for drinking water states that for treated water no more than 1 of 10 analytical units should have an MPN value of $>2.2 \mathrm{MPN} / 100 \mathrm{ml}$ of water and no analytical unit should have an MPN value of $>9.2 \mathrm{MPN} / 100 \mathrm{ml}$ [7]. Out of the 30 samples only 10 had an MPN value of $<2.2$ representing $33 \%$. Only two out of the ten brands of sachet water sampled had an average MPN value of $<2.2$ (KD and $\mathrm{G}$ brands).

From the data $36.6 \%(11 / 30)$ of the individual samples had more than 10 total coliform per $100 \mathrm{ml}$ of water. Ideally there should be no coliform per $100 \mathrm{ml}$ of water for treated water [7] and only $16.7 \%$ (5/30) of the samples fell within this criterion.

The total coliform count of the various brands was found to be high. The level of coliform bacteria in the sachet water from the various brands sampled did not meet the WHO guidelines for drinking water [7]. None of the brands met these criteria as shown from their mean MPN index. This finding compares with a similar study done in Cape Coast, the capital of the Central Region of Ghana which reported that various brands of sachet water produced in the municipality were contaminated with coliforms [8]. A similar study in Osogbo Metropolis of Nigeria which compared the MPN values of sachet water, tap water and well water recorded 0 to 1 coliform $/ 100 \mathrm{ml}$ for sachet water [9]. In that study the sachet water was found to be of good quality.

When water supplies contain coliform bacteria in levels greater than one per $100 \mathrm{ml}$ of water, the water may also contain pathogens that cause acute intestinal illness. While generally considered a discomfort to health, these infections may be fatal for infants, the elderly and those who are sick [9].

The coliform-positive samples were also tested for faecal coliform. Faecal coliform is considered more as an indicator of faecal contamination because whereas coliform can exist in the environment, faecal coliform are non-disease causing organisms which are found in the intestinal tract of warm blooded animals hence its presence is indicative of pollution with animal or human waste [10]. They are primarily used to indicate the presence of bacterial pathogens such as Salmonella spp., Shigella spp., Vibrio cholerae, Campylobacter jejuni, Campylobacter coli, Yersinia enterocolitica and pathogenic E. coli. These organisms can be transmitted via the faecal/oral route

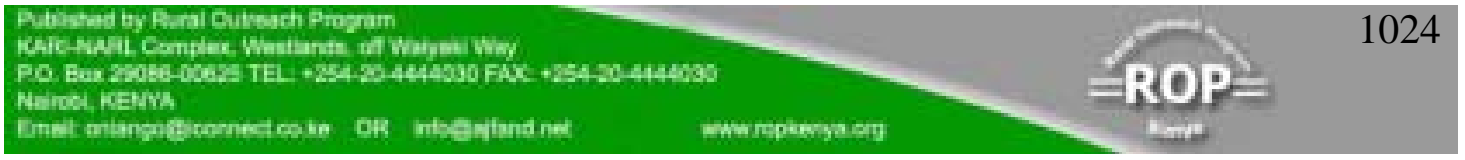




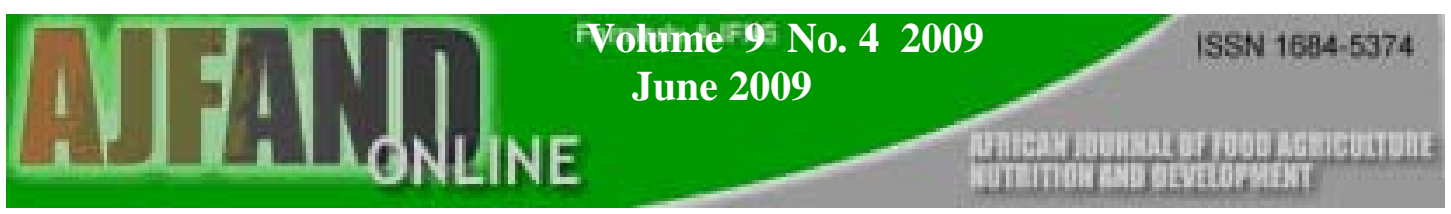

by contaminated or poorly treated water and may cause diseases such as gastroenteritis, salmonellosis, dysentery, cholera and typhoid fever.

Six of the samples were positive for faecal coliform and two of these were from brand $\mathrm{P}$, and one each from brand ST, G, J and K. The presence of faecal coliform observed in packaged water has been reported to be due to poor hygienic practices of producers, failure to wash hands, ignorance about good hygienic practices as well as the presence of animals in the vicinity of the factory [11].

All the six faecal coliform-positive samples were tested for E. coli and two of them were found to be positive, all from brand P. The presence of E.coli, a faecal coliform is a strong indicator of recent sewage or animal waste contamination. Treated water should not contain this organism because it is also an indicator microorganism for other pathogens that may be present in faeces [12]. In a similar study done in Ibadan, Nigeria $6.4 \%$ of the sachet water samples tested fielded bacteria growth with organisms such as Klebsiella, Streptococcus and Pseudomonas [13]. E.coli and coliforms above the WHO standards were also reported from a Port Harcourt, Nigeria study that fielded five brands of sachet water [14]. In a recent study in Ghana looking at enteric pathogenic protozoan organisms in sachet water, $77 \%$ of the samples were found to contain infective stages of pathogenic parasitic organisms such as Microsporidia sp, Cryptosporidium parvum, Cyclospora cayetenensis, Sarcocystis sp etc. [15].

Water that has been treated for the purpose of drinking should not be contaminated with coliform; if present then the source of the contamination must be located. Sachet water is sold to the public for direct consumption hence is supposed to undergo treatment. In Ghana the water source for the production of the sachet water is piped water supplies or well water [5] which is then supposedly further treated to make it safe for direct consumption hence sachet water is regarded as treated water. The source of water for sachet water, therefore, cannot be compared to natural mineral waters, which are the usual source for bottled water in the developed world, which may not be entirely free of bacterial contamination [16]. Most bacteria are thought to enter as contaminants during bottling or bagging. A study done on piped water in some suburbs in Ghana reported contamination with faecal coliforms at levels of between 10 and 28 per $100 \mathrm{ml}$ [17].

In the case of sachet water the sources of contamination could be the main water source because it is reported that some unscrupulous producers just bag and seal pipe water without any form of treatment [18].

Poorly maintained filter systems are also a possible source of contamination because bacteria can grow on filters if these are not changed regularly, and thereafter enter the water supply. It has been shown that charcoal filters used in removing unpleasant odours from drinking water can support large bacterial numbers. Bacteria count as high as $7 \times 10^{6} / \mathrm{ml}$ were detected in the effluent from a charcoal filter 6 days after installation [19]. Most Ghanaian sachet water producers use beds or columns of ion

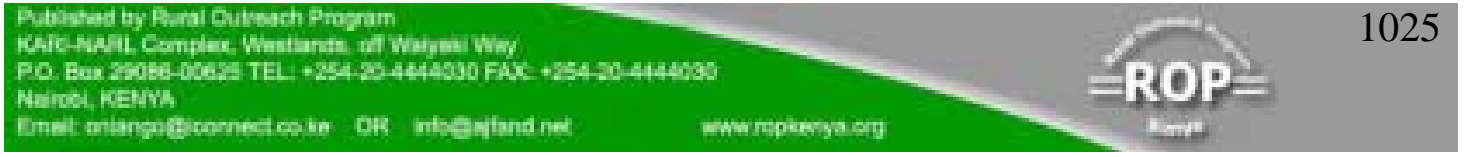


exchange resins or activated carbon but these can also support similar bacterial growth unless properly maintained and serviced [5].

The rubbers used in packaging the water if not properly sterilized and the generally unhygienic manners in which some of these products are hawked in the streets may also be sources of contamination.

In a study carried out in Lagos, Nigeria, enteric pathogens and E. coli were not isolated from any samples and brands of sachet water but formed a significant part of the isolates on the sachet surfaces of samples collected from the cooling receptacles (pail, wheel barrow and refrigerator). Similar species of bacteria were isolated from waste water and surface of the sachets, with the waste water containing significantly higher numbers of bacteria [20]. The various analyses on the quality of sachet water from different localities across Africa including this study have demonstrated that sachet water is of variable safety and quality. Sachet water is affordable from the perspective of consumers and for producers is a lucrative business but the results from the many studies raise public health concerns that need to be addressed.

\section{CONCLUSION}

The primary objective of monitoring drinking water is to protect the health of the community by preventing the spread of water-borne diseases. The peculiar situation of sachet water is that most of the producers are not registered hence monitoring becomes difficult. The Food and Drugs Board of Ghana, as the regulatory authority should therefore insist on official registration of all producers and publish regularly the list of producers who have registered their products, conduct routine tests on these products and alert consumers about those with the unwholesome products. Most households in Ghana now rely on sachet water as their main source of drinking water hence if contaminated products get onto the market, the consequences could be fatal.

It is obvious from the study that some of the sachet water being sold in Teshie and Nungua in Accra Ghana and in the other suburbs of the city may be safe as far as bacteriological quality is concerned but a lot more of these products are unsafe for drinking. Regrettably the consumer has no way of knowing which product is safe and which one is not. It therefore behooves the regulatory authorities to employ adequate measures to protect the consumer because sachet water has come to stay and the producers are increasing by the day.

\section{ACKNOWLEDGEMENT}

We are grateful to the vendors and producers recruited into the study and the staff of the Bacteriology Department of the Noguchi Memorial Institute for Medical Research, Legon, for their support in ensuring the success of the study. 


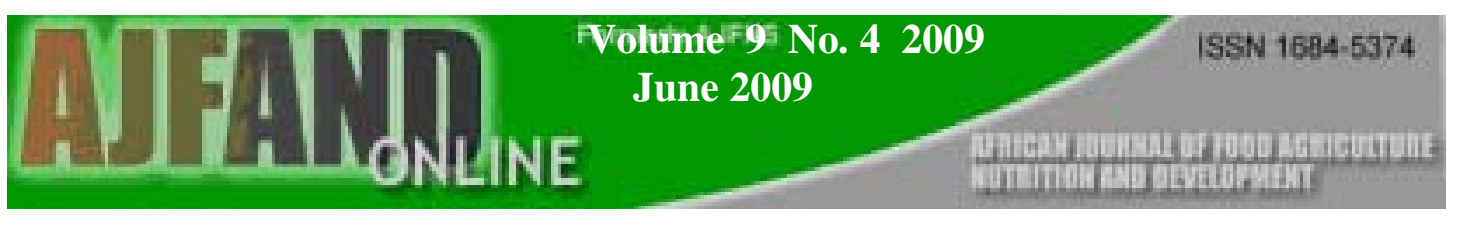

Table 1: MPN values of the 10 brands of sachet water

\begin{tabular}{|l|l|l|l|l|}
\hline Brand & \multicolumn{5}{|c|}{ MPN INDEX OF SAMPLES } \\
\hline & First (1) & Second (2) & Third (3) & Mean \\
\hline S & 14 & 4 & 11 & 9.7 \\
\hline KD & 2 & 0 & 2 & 1.3 \\
\hline B & 50 & 4 & 8 & 20.7 \\
\hline G & 0 & 4 & 2 & 2 \\
\hline ST & 7 & 2 & 4 & 4.3 \\
\hline C & 23 & 0 & 4 & 9 \\
\hline A & 11 & 0 & 7 & 6 \\
\hline P & 110 & 23 & 50 & 61 \\
\hline K & 90 & 0 & 17 & 35.7 \\
\hline J & 11 & 2 & 7 & 6.7 \\
\hline
\end{tabular}

Table 2: Brands of samples contaminated with Faecal coliform and $E$. coli

\begin{tabular}{|l|l|l|}
\hline Brand & Faecal coliform & Pathogenic E.coli \\
\hline P1 & Present & Present \\
\hline P2 & Present & Present \\
\hline ST & Present & Absent \\
\hline G & Present & Absent \\
\hline J & Present & Absent \\
\hline K & Present & Absent \\
\hline
\end{tabular}




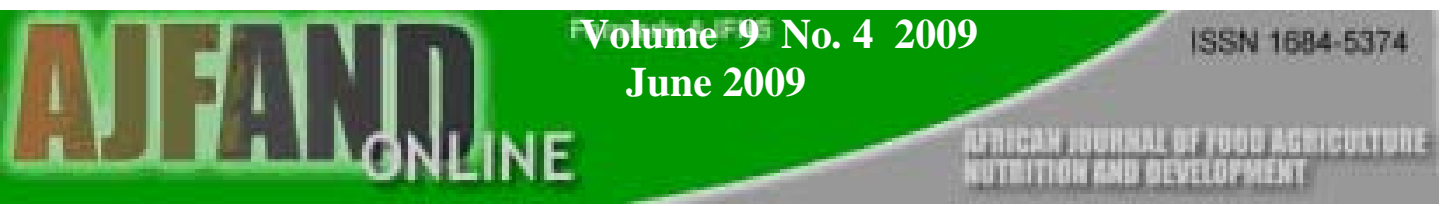

Table 3: Classification of the samples according to WHO criteria for drinking water

\begin{tabular}{|l|l|l|l|l|}
\hline Class & Grade & $\begin{array}{l}\text { Presumptive } \\
\text { count } \\
(\text { Per 100ml) }\end{array}$ & $\begin{array}{l}\text { Number of } \\
\text { Samples } \\
(\mathbf{n = 3 0 )}\end{array}$ & $\begin{array}{l}\text { Percentage } \\
(\mathbf{1 0 0 \%})\end{array}$ \\
\hline I & Excellent & 0 & 5 & 16.7 \\
\hline II & Satisfactory & $1-3$ & 5 & 16.7 \\
\hline III & Suspicious & $4-10$ & 9 & 30.0 \\
\hline IV & Unsatisfactory & $>10$ & 11 & 36.6 \\
\hline
\end{tabular}




\section{REFERENCES}

1. Third World Water Forum, Blockade, Myth, Illusions in development and cooperation, 2003; volume 30, No. 1.

2. Gadgil A Drinking water in developing countries. Annual review of energy and the environment 1998; 23:253-286.

3. Anonymous. All Africa.com: The supply side constraints of Ghana's water sector, 2006. allafrica.com/stories/200611281208.

4. Dufour A, Snozzi M, Koster W, Bartram J, Ronchi E and L Fawtrell Assessing microbial safety of drinking water, improving approaches and methods, WHO/OECD, 2003; p.11.

5. Obiri DK, Okore-Hanson A and $\mathbf{K}$ Jones The microbiological quality of drinking water sold on the streets in Kumasi, Ghana. Letters in Applied Biology 2003; 37:334.

6. Lindsay M My work at Enterprise works Ghana, travelblog.org/Africa/Ghana, www.travelblog.org/Africa/Ghana/Greater-Accra/Accra/blog-15055.html - 51k July 28 th 2005.

7. World Health Organization Report Guidelines for drinking water supply. WHO, Geneva, 1985. 585Pp.

8. Dodoo DK, Quagraine EK, Okai-Sam F, Kambo DJ and JV Headley Quality of "sachet" water in the Cape Coast municipality J Environ Sci. Health 2006; 3:329-342.

9. Olowe OA, Ojurongbe O, Opaleye OO, Adedosu OT, Olowe RA and KIT Eniola Bacteriological quality of water samples in Osogbo Metropolis. African Journal of Clinical and Experimental Microbiology 2005; 6 (3): 219-222.

10. Standard Methods for the Examination of Water and Wastewater, $18^{\text {th }}$ Edition, WPCF; Water Pollution Control Federation, Washington, DC, 1992.

11. Coroler L, Elomari M, Hoste B, Gillis M, Izard D and H Leclerc Pseudomonas rhodesiae sp. Nov., a new species isolated from natural mineral waters. Systematic and applied Microbiology 1996; 19: 600-607.

12. U.S Environmental Protection Agency, Ground water and Drinking water- $E$. coli 015:H7 in Drinking water, 2003.

13. Adenkunle LV, Sridhar MKC, Ajayi AA, Oluwade PA and JF Olawuyi An assessment of the health and social economic implications of sachet water in

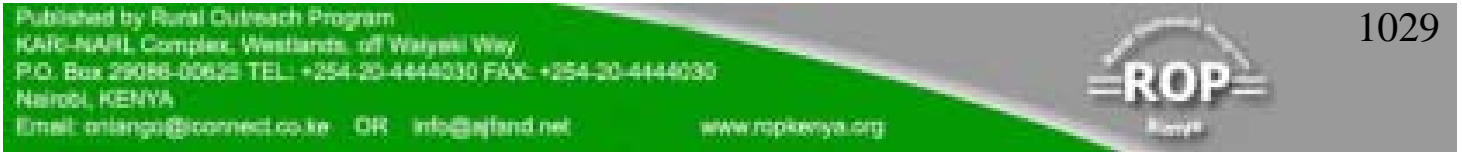


Ibadan Nigeria: A public health challenge. African Journal of Biomedical Research 2004; 7 (1): 5-8.

14. Ifeanyi VO, Obiekezie SO, Udebuani AC and PN Abara Quality evaluation of sachet water sold in Port Harcourt, Nigeria. International Journal of Natural and Applied Sciences 2006; 2 (4): 332-335.

15. Kwakye-Nuako G, Borketey PB, Mensah-Attipoe I, Asmah RH and PF Ayeh-Kumi Sachet drinking water in Accra: the potential for transmission of enteric pathogenic protozoan organisms. Ghana Medical Journal 2007; 41 (2): 62-66.

16. Defives C, Guyard S, Oulare M.M, Mary P and JP Hornez Total counts, culturable and viable and non-culturable microflora of a French mineral water: a case study. Journal of Applied Microbiology 1999; 86: 1033-1038.

17. Quist KA Faecal indicators in drinking water in the urban area in Kumasi. MSc. dissertation, Biological Sciences, Kwame Nkrumah University of Science and Technology, Kumasi Ghana, 1999.

18. Nwosu JN and CC Ogueke Evaluation of Sachet Water Samples in Owerri Metropolis. Nigerian Food Journal 2004; 22: 164-170.

19. Hunter PR and SH Burge The bacteriological quality of natural mineral waters. Epidemiology and Infection 1987; 99: 439-443.

20. Egwari LO, Iwuanyanwu S, Ojelabi, CI, Uzochukwu O and WW Effiok Bacteriology of sachet water sold in Lagos, Nigeria. East African Medical Journal 2005; 82 (5): 235-240. 